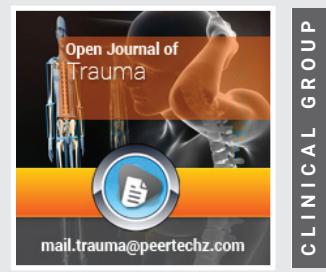

\title{
The dual mobility hip arthroplasty for hip fracture in Parkinson's disease
}

\author{
Ayman Abdelaziz Bassiony ${ }^{1 *}$ and Saleh Gameel ${ }^{2}$ \\ ${ }^{1}$ Professor of Orthopedic Surgery, Ain Shams University, Egypt \\ ${ }^{2}$ Lecturer of Orthopedic Surgery, Ain Shams University, Egypt
}

Received: 15 June, 2020

Accepted: 27 June, 2020

Published: 29 June, 2020

*Corresponding author: Ayman Abdelaziz Bassiony, MD, Professor of Orthopedic Surgery, Ain Shams University, Egypt, Tel: 01001625333 ;

E-mail: aymanbassiony@yahoo.com

Keywords: Parkinson's Disease; Fractures of the femoral neck; Dual mobility; Hip arthroplasty

https://www. peertechz.com

\section{Check for updates}

\begin{abstract}
Backgroud: Patients with Parkinson's disease are at increased risk for falls and associated hip fractures as a result of tremor, rigidity, and postural instability. The available literature is limited and conflicting regarding the optimal surgical treatment and risk for postoperative complications and mortality in this unique patient population. This study question the effectiveness of dual mobility hip arthroplasty in Parkinson's disease patients with proximal femoral fractures.

Patients and methods: Twelve patients (13 hips) with proximal femoral fracture (fracture neck of femur in 6 cases, unstable trochanteric fracture in 5 cases and failed fixation of trochanteric fracture in 2 case). Cemented dual mobility acetabular components were used in 9 patients and a cementless dual mobility acetabular components was used in 4 patient. Follow up reports on:postoperative complication rates, in-hospital mortality, length of hospital stay, discharge status, mortality rate, recovery of prefracture ambulatory ability, and return to prefracture activities of daily living. The mean age 65 years and the mean follow-up 32 months.
\end{abstract}

Results: We did not encounter any case of dislocation of the prosthesis. Seven out of 13 patients returned to pre-fracture activities of daily living with the same disability stage while 5 patients had worsening in disability by 1 stage.

Conclusion: Dual mobility THA in the Parkinsonean patients provides both efficacy and stability with good functional results.

\section{Introduction}

The prevalence of Parkinson's disease and the incidence of hip fractures mirror an ageing population living longer [1,2]. Parkinson's disease patients with hip fractures stay at higher risk of mortality and surgical and medical complications [3]. Short- and long-term results in patients with Parkinson's disease following hip fracture are generally described to be worse than in patients without this disease [4].

Many of these patients experience hip fracture that results in even more limitation of their mobility and may require a Total Hip Arthroplasty (THA). Postoperatively, these patients may have higher rates of dislocation or periprosthetic fractures due to PD-associated falls [5]. As a result, orthopedic surgeons may hesitate to offer THA as a treatment to these patients. Because of advances in arthroplasty technology and the medical management of the $\mathrm{PD}$, increasing numbers of PD patients undergo THA $[6,7]$.
According to the literature, the rate of dislocation after THA in patients with PD is $0 \%-37 \%[8,9]$. The neurological conditions such as neuromuscular weakness can predispose patients to gait disturbance, fall, functional disturbance, and dislocation after THA [24]. PD patients are a high-risk group for dislocation after primary and revision THAs because of increased muscle tone and rigidity [9].

The available literature is limited and conflicting regarding the optimal surgical treatment and risk for postoperative complications and mortality in this unique patient population. The aim of the study was to report the clinical outcomes following dual mobility total hip arthroplasty in Parkinson's disease patients with proximal femoral fractures.

\section{Materials and methods}

The aim of the study was to report the clinical outcomes following dual mobility total hip arthroplasty in Parkinson's disease patients with proximal femoral fractures. 
The modified Hoehn and Yahr scale is used system for describing how the symptoms of Parkinson's disease progress [10]. Accordingly the patients were divided into, 2 cases (stage 1), 6 cases (stage 2) and 5 cases (stage 3) Table 1.

Twelve patients (13 hip) with proximal femoral fracture (fracture neck of femur in 6 cases, unstable trochanteric fracture in 5 cases (A2.2 and A2.3 per-trochantric according to $\mathrm{AO}$ classification) and failed fixation of trochanteric fracture in 2 case). The mean age 65 years and the mean follow-up 32 months (Table 2).

All 13 patients were operated using a modified lateral approach. The preservation of the gluteii, their nerve supply, and muscular attachment to the femur were of utmost importance. We preferred to suspend the gluteus medius and gluteus minimus on stay sutures and re-suture them again at the end of operation rather than to detach them from the bone. This preserves the gluteus minimus and avoids injury to the most distal branch of the superior gluteal nerve.

Cemented dual mobility acetabular components were used in 9 patients and a cementless dual mobility acetabular components was used in 4 patient .Cemented standerd femoral components were used in one patients, a cementless standerd stem was used in 7 patients, cemented long stem in 1 patients (Figure 1) and cementless revision stem was used in 4 patients

Table 1: Modified Hoehn and Yahr Scale for staging of Parkinson's disease.

\begin{tabular}{|c|c|}
\hline Stage & Modified Hoehn and Yahr Scale \\
\hline 1 & Unilateral involvement only \\
\hline 1.5 & Unilateral and axial involvement \\
\hline 2 & Bilateral involvement without impairment of balance \\
\hline 2.5 & Mild bilateral disease with recovery on pull test \\
\hline 3 & Mild to moderate bilateral disease; some postural instability; physically \\
\hline 4 & independent \\
\hline 5 & Severe disability; still able to walk or stand unassisted \\
\hline
\end{tabular}

According to the patients' general condition, immediate admission to the intensive care unit postoperatively for at least overnight observation was needed. Parenteral anticoagulation (enoxaparin-low molecular weight heparin) started $12 \mathrm{~h}$ postoperatively then dose adjustment and shifting to oral anticoagulant were managed in conjunction with the neurologist. All patients received prophylactic anticoagulation for at least 4 weeks. Assisted weight bearing is allowed as soon as the general condition of the patient permits under physiotherapist supervision. The figure of four positions, cross leg adduction, extreme lower limb rotations, and hip flexion of more than $100^{\circ}$ positions were instructed to the patient's care givers to be prohibited. Abduction pillow was advised for at least 6 weeks postoperatively.

Immediate postoperative $\mathrm{X}$-ray was done for all patients to assess component alignment and stability and was repeated with every follow-up.

Follow-up was done 3 weeks postoperatively for the removal of stitches, then regularly at 6 weeks, 12 weeks then every 6 months for the first 2 years postoperatively. Examined outcomes were postoperative complication rates; in-hospita mortality; length of hospital stay; discharge status, mortality rate, recovery of prefracture ambulatory ability, and return to prefracture activities of daily living.

\section{Results}

The operative time ranged from one and half hours to three hours with a mean blood loss of $500 \mathrm{cc}$. All the patients were discharged in average of 4 days. Two peri-prosthetic fractures had been encountered (one patient fell 2 months after total hip arthroplasty and one patient 32 months after initial surgery) and were treated operatively by wire fixation as the implant was found to be stable (Figure 2).

One late periprosthetic infection occurred 16 months postoperatively and antimicrobial suppression was chosen because comorbidities did not allow additional surgery.

Table 2: The demographic data of the study group.

\begin{tabular}{|c|c|c|c|c|c|c|c|c|}
\hline Case & Age & Sex & Diagnosis & $\begin{array}{c}\text { Stage } \\
\text { H-Y Scale }\end{array}$ & Acetabular side & Femoral side & discharge & Follow up \\
\hline 1 & 72 & $\mathrm{~F}$ & Unstable pertrochantric fracture & 3 & Cemented dual mobility cup & Cemented long stem & Walking with walker & 30 \\
\hline 2 & 66 & M & Unstable pertrochantric fracture & 3 & Cemented dual mobility cup & Cemented standerd stem & Walking with walker & 36 \\
\hline 3 & 63 & $\mathrm{~F}$ & Fracture neck of femur & 2 & Cemented dual mobility cup & Cementless standerd stem & Walking with 2 cruches & 54 \\
\hline 4 & 80 & $\mathrm{~F}$ & Fracture neck of femur & 1 & Cementless dual mobility cup & Cementless standerd stem & Walking with 2 cruches & 30 \\
\hline 5 & 60 & M & $\begin{array}{l}\text { Failed fixation of trochanteric } \\
\text { fracture }\end{array}$ & 2 & Cemented dual mobility cup & Cementless standerd stem & Walking with 2 cruches & 36 \\
\hline 6 & 70 & M & Fracture neck of femur & 1 & Cementless dual mobility cup & Cementless standerd stem & Walking with walker & 30 \\
\hline 7 & 65 & $\mathrm{~F}$ & $\begin{array}{l}\text { Failed fixation of trochanteric } \\
\text { fracture }\end{array}$ & 3 & Cementless dual mobility cup & Cementless long stem & Walking with walker & 24 \\
\hline 8 & 67 & M & Fracture neck of femur & 2 & Cemented dual mobility cup & Cementless standerd stem & Walking with 2 cruches & 32 \\
\hline 9 & 60 & M & Unstable pertrochantric fracture & 2 & Cemented dual mobility cup & Cementless long stem & Walking with 2 cruches & 24 \\
\hline 10 & 59 & $\mathrm{~F}$ & Unstable pertrochantric fracture & 3 & Cemented dual mobility cup & Cementless long stem & Walking with 2 cruches & 30 \\
\hline 11 & 66 & $\mathrm{~F}$ & Unstable pertrochantric fracture & 3 & Cemented dual mobility cup & Cemented long stem & Walking with walker & 24 \\
\hline 12 & 62 & M & Fracture neck of femur & 2 & Cementless dual mobility cup & Cementless standerd stem & Walking with 2 cruches & 36 \\
\hline 13 & 65 & M & Fracture neck of femur & 2 & Cemented dual mobility cup & Cementless standerd stem & Walking with 2 cruches & 30 \\
\hline
\end{tabular}

Citation: Bassiony AA, Gameel S (2020) The dual mobility hip arthroplasty for hip fracture in Parkinson's disease. Open J Trauma 4(1): 032-035. 

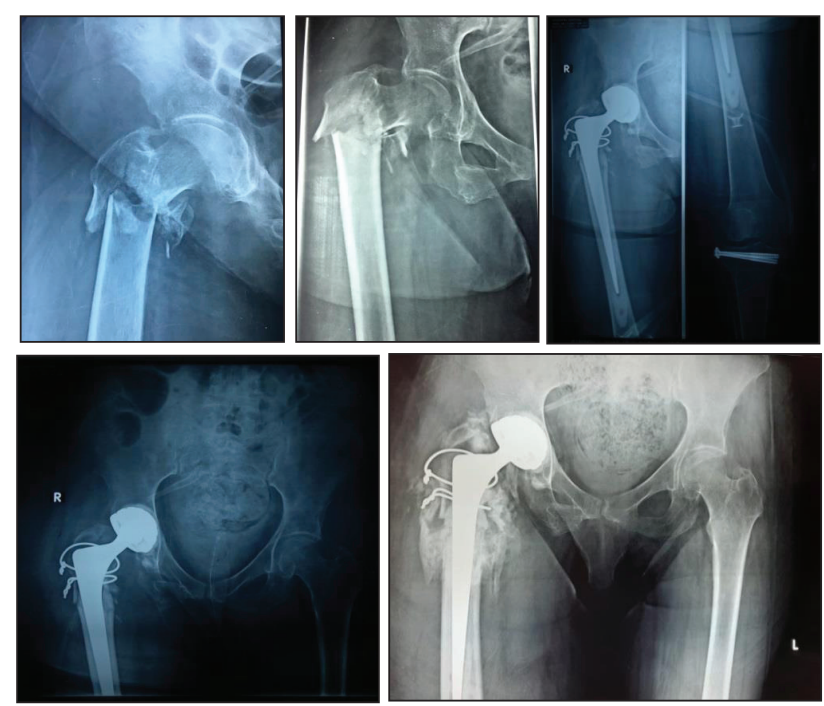

Figure 1: Female patient 66 years old with unstable comminuted per-trochantric fracture that underwent cemented dual mobility hip wit cemented long stem, 2 years follow up with good functional results.
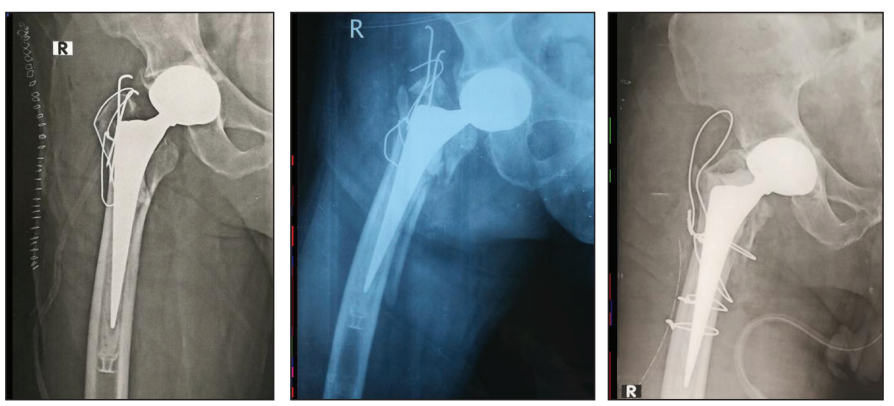

Figure 2: Unstable per-tochantric fracture treated with cemented dual mobility hip had periprosthetic fracture that was fixed with wires.

Throughout the whole follow-up period, urinary tract infection and chest infection were the most frequent medical complications (coincident respiratory and urinary tract infections were recorded in 5 patients) and were treated with antibiotics. No in hospital perioperative deaths occurred. One patient died with severe chest infection 6 months after surgery. We did not encounter any case of dislocation of the prosthesis. Seven out of 13 patients returned to prefracture activities of daily living with the same disability stage according to the Hoehn and Yahr classification while 5 patients had worsening in disability by 1 stage.

\section{Discussion}

Parkinson's Disease (PD) is the second most common neurodegenerative disease (after Alzheimer's disease) with a life expectancy of 7-14years. The motor symptoms of PD are the most prominent including bradykinesia, muscular rigidity, rest tremor, and postural and gait impairment [11]

Patients with Parkinson's Disease (PD) have a heightened risk of sustaining hip fractures due to disturbed balance and gait insecurity. Most Parkinson's disease patients experience falls as a result of disease symptoms and many have recurrent episodes [12]. It was estimated that $60.5 \%$ of patients with
Parkinson disease experience at least one episode and 39\% have recurrent falls [13]. The high frequency of falls consequently contributes to the increased fracture risk

Several studies have reported a higher risk of bone fractures in patients with Parkinson's disease compared to the general population $[14,15]$. The higher risk of fracture in these patients is due to postural instability that increases the risk of fall, reduced bone mineral density due to reduced physical activity, vitamin D deficiency from lack of exposure to UV radiation and secondarily from immobilization- induced hypercalcemia [16].

Short- and long-term outcomes in patients with Parkinson's disease following hip fracturee are generally considered to be worse than patients without Parkinson's disease despite similar hospital experiences [17].

Although the mortality rate in patients with Parkinson's disease undergoing surgery for fracture of the proximal femur is comparable to the general population, the morbidity is higher in these patients [18]. Rehabilitation should be started early, as soon after postoperative stabilization of the patient in order to minimize complications and achieve the maximum degree of physical activity. According to literature, very poor results were seen after hemiarthroplasty in patients with Parkinson's disease who were not mobilized in the first week after surgery (37\% dislocation, $49 \%$ of pressure ulcers, $75 \%$ mortality) [19].

Dual Mobility Cups (DMCs) (also known as unconstrained tri-polar implants) are indicated in THA when the risk of instability is great especially in patients with neurological deficit. In our group of operated patients, mobilization was started on the first postoperative day and there was no case of prosthesis dislocation, which can be attributed to the implant choice,surgical technique, intensive postoperative rehabilitation, and patient's care.

Initially the hip arthroplasty was not recommended for the treatment of femoral neck fractures in patients with Parkinson's disease because of very high incidence of dislocation (37\%) and mortality (75\%). Deaths of all patients with dislocation of the prosthesis within 6 months after surgery were published by Coughlin [19]. This observation was not confirmed in our study, but one of our patients died within 6 months after surgery for severe chest infection. Although variable mortality following hip fracture in Parkinson's disease patients has been reported, we found it comparable with 1-year mortality published in non- Parkinson's disease patients.

Current literature is scarce and conflicting regarding optimal surgical management, revision rate, and complications after internal fixation or prosthetic replacement of hip fractures in patients with Parkinson's disease. Some authors have noted excessively high dislocation rates in patients treated with hemiarthroplasty, leading to the conclusion that even displaced fractures should be treated with internal fixation [20]. However according to Karadsheh et al2015, failure of fixation for patients treated with internal fixation of non-displaced femoral neck fractures, as defined by the need for a revision operation, is significantly higher in the Parkinson's disease compared with non-Parkinson's (22\% versus $5 \% ; p=0.01$ ) [21]. 
Despite the increase in interest in the application of arthroplasty procedures in patients with $\mathrm{PD}$, data on outcomes of these procedures are still relatively scarce. Therefore, this study sought to illuminate outcomes as well as rates of complications in a group of parkinsonian patients with proximal femoral fractures.

We did not encounter any case of dislocation of the prosthesis, which is often mentioned as a main complication in the literature. However, the specific complications related to the use of dual mobility hip should be noted, these are periprosthetic fractures in the postoperative period resulting from falls due to the neurological disease.Falls in the period after total hip arthroplasty may result in serious periprosthetic fractures of the femur as is seen in $8.3 \%$ of hip joints in our study. It is necessary for the multidisciplinary team to pay more attention to preventing falls during the postoperative period.

Dual mobility cups were efficient in reducing THA dislocations in Parkinson's patients who are at more risk of instability due to neurologic impairment. Furthermore, they gave good functional results. Based on our findings, we recommend DM cups for all patients with a higher risk of dislocation. The dual mobility cups may give an answer to the instability issues in the patients with weaker neuromuscular control like Parkinson's disease.

\section{References}

1. Pringsheim T, Jette N, Frolkis A, Steeves TDL (2014) The prevalence of Parkinson's disease: a systematic reviewandmetaanalysis. Mov Disord 29: 1583-1590. Link: https://bit.ly/2Vmst6z

2. Brauer CA, Coca-Perraillon M, Cutler DM, Rosen AB (2009) Incidence and mortality of hip fractures in the United States. The J Am Med Assoc 302: 1573 1579. Link: https://bit.ly/31/4Cbu

3. Critchley RJ, Khan SK, Yarnall AJ, Parker MJ, Deehan DJ (2015) Occurrence, management and outcomes of hip fractures in patients with Parkinson's disease. Br Med Bull 115: 135-142. Link: https://bit.ly/2ZfXdrj

4. Walker RW, Chaplin A, Hancock RL, Rutherford R, Gray WK (2013) Hip fractures in people with idiopathic Parkinson's disease: incidence and outcomes. Mov Disord 28: 334-340. Link: https://bit.ly/3dAGgwE

5. Weber M, Cabanela ME, Sim FH, Frassica FJ, Harmsen WS (2002) Total hip replacement in patients with Parkinson's disease. Int Orthop 26: 66-68. Link: https://bit.ly/3dC9QSk

6. Harwin SF, Mistry JB, Chughtai M, Khlopas A, Gwam C, et al. (2017) Dual mobility acetabular cups in primary total hip arthroplasty in patients at high risk for dislocation. Surg Technol Int 30: 251-258. Link: https://bit.ly/2VhztBK
7. Mathew PG, Sponer P, Kucera T, Grinac M, Knizek J (2013) Total HIP arthroplasty in patients with Parkinson's disease. Acta Med (Hradec Kralove) 56: 110-116. Link: https://bit.ly/2YDj8tn

8. Cabanela ME, Weber M (2000) Total hip arthroplasty in patients with neuromuscular disease. Instr Course Lect 49: 163-1688. Link: https://bit.ly/2BE26IR

9. Fackler CD, Poss R (1980) Dislocation in total hip arthroplasties. Clin Orthop Relat Res 151: $169 \mathrm{e} 78$.

10. Goetz CG, Poewe W, Rascol O, Sampaio C, Stebbins GT, et al. (2004) Movement Disorder Society Task Force Report on the Hoehn and Yahr Staging Scale: Status and Recommendations. The Movement Disorder Society Task Force on Rating Scales for Parkinson's Disease. Mov Disord 19: 1020-1028. Link: https://bit.ly/2Nz8eP0

11. Kalia LV, Lang AE (2015) Parkinson's disease. Lancet (London, England). 386 896-912. . Link: https://bit.ly/2B3Afvt

12. Kalilani L, Asgharnejad M, Palokangas T, Durgin T (2016) Comparing the incidence of falls/fractures in Parkinson's disease patients in the US population. PLoS ONE 11: e0161689. Link: https://bit.ly/2BCha3f

13. Allen NE, Schwarzel AK, Canning CG (2013) Recurrent falls in Parkinson's disease: a systematic review. Parkinsons Dis 2013: 906274. Link: https://bit.ly/2Z4XDQU

14. Genever RW, Downes TW, Medcalf $P$ (2005) Fracture rates in Parkinson's disease compared with age- and gender matched controls: A retrospective cohort study. Age Ageing 34: 21-24. Link: https://bit.ly/2BDVaoO

15. Johnell O, Melton LJ, Atkinson EJ, O’Fallon WM, Kurland LT (1992) Fracture risk in patients with Parkinsonism: A population-based study in Olmsted County, Minnesota. Age Ageing 21: 32-38. Link: https://bit.ly/385AamX

16. Kao CH, Chen CC, Wang SJ, Chia LG, Yeh SH (1994) Bone mineral density in patients with Parkinson's disease measured by dual photon absorptiometry. Nucl Med Commun 15: 173-177. Link: https://bit.ly/3g0gBPz

17. Walker RW, Chaplin A, Hancock RL, Rutherford R, Gray WK (2013) Hip fractures in people with idiopathic Parkinson's disease: incidence and outcomes. Mov Disord 28: 334-340. Link: https://bit.ly/3dAGgwE

18. Hammer AJ (1991) Intertrochanteric and femoral neck fractures in patients with parkinsonism. S Afr Med J 79: 200-202. Link: https://bit.ly/2ZfVFOt

19. Coughlin L, Tempelton J (1980) Hip fractures in patients with Parkinson's disease. Clin Orthop Relat Res 192-195. Link: https://bit.ly/2NyWsUw

20. Turcotte R, Godin C, Duchesne R, Jodoin A (1990) Hip fractures and Parkinson's disease: a clinical review of 94 fractures treated surgically. Clin Orthop Relat Res 132-136. Link: https://bit.ly/31jtTCB

21. Karadsheh MS, Rodriguez EK, Harris MB, Zurakowski D, Lucas R, et al. (2015) Mortality and Revision Surgery Are Increased in Patients With Parkinson's Disease and Fractures of the Femoral Neck. Clin Orthop Relat Res 473: 3272 3279 Link: https://bit.ly/31ljB4T

Copyright: ( $) 2020$ Bassiony AA, et al. This is an open-access article distributed under the terms of the Creative Commons Attribution License, which permits unrestricted use, distribution, and reproduction in any medium, provided the original author and source are credited.

Citation: Bassiony AA, Gameel S (2020) The dual mobility hip arthroplasty for hip fracture in Parkinson's disease. Open J Trauma 4(1): 032-035. 